\title{
BMJ Open Incidence and risk factors for hospital- acquired infection among paediatric patients in a teaching hospital: a prospective study in southeast Ethiopia
}

\author{
Biniyam Sahiledengle (D) , ${ }^{1}$ Fekadu Seyoum, ${ }^{2}$ Daniel Abebe ${ }^{2}$ \\ Eshetu Nigussie Geleta, ${ }^{3}$ Getahun Negash, ${ }^{3}$ Abdurhaman Kalu, ${ }^{1}$ \\ Demelash Woldeyohannes, ${ }^{1}$ Yohannes Tekalegn (D) , ${ }^{1}$ Demisu Zenbaba, ${ }^{1}$ \\ Bruce John Edward Quisido ${ }^{4}$
}

To cite: Sahiledengle B, Seyoum F, Abebe D, et al. Incidence and risk factors for hospital-acquired infection among paediatric patients in a teaching hospital: a prospective study in southeast Ethiopia. BMJ Open 2020;10:e037997. doi:10.1136/ bmjopen-2020-037997

- Prepublication history and additional material for this paper are available online. To view these files, please visit the journal online (http://dx.doi org/10.1136/bmjopen-2020037997).

Received 25 February 2020 Revised 10 November 2020 Accepted 20 November 2020

D Check for updates

(c) Author(s) (or their employer(s)) 2020. Re-use permitted under CC BY-NC. No commercial re-use. See rights and permissions. Published by BMJ.

For numbered affiliations see end of article.

\section{Correspondence to} Mr Biniyam Sahiledengle; biniyam.sahiledengle@gmail. com

\section{ABSTRACT}

Objectives In order to maximise the prevention of hospital-acquired infections (HAls) and antimicrobial resistance, data on the incidence of HAls are crucial. In Ethiopia, data about the occurrence of HAls among hospitalised paediatric patients are lacking. We aim to determine the incidence and risk factors of HAls among paediatric patients in Ethiopia.

Design A prospective cohort study.

Setting A teaching hospital in southeast Ethiopia. Participants 448 hospitalised paediatric patients admitted between 1 November 2018 and 30 June 2019.

Primary and secondary outcome measures Incidence and risk factors of hospital-acquired infections.

Results A total of 448 paediatric patients were followed for 3227 patient days. The median age of the patients was 8 months (IQR: 2-26 months). The incidence rate of HAls was 17.7 per 1000 paediatric days of follow-up; while the overall cumulative incidence was $12.7 \%$ (95\% Cl 9.8\% to $15.8 \%$ ) over 8 months. Children who stayed greater than 6 days in the hospital (median day) (adjusted risk ratio (RR): $2.58,95 \% \mathrm{Cl} 1.52$ to 4.38 ), and children with underlying disease conditions of severe acute malnutrition (adjusted RR: 2.83, 95\% $\mathrm{Cl} 1.61$ to 4.97 ) had higher risks of developing HAls.

Conclusions The overall cumulative incidence of HAls was about 13 per 100 admitted children. Length of stay in the hospital and underlying conditions of severe acute malnutrition were found to be important factors associated with increased risk of HAls.

\section{INTRODUCTION}

There is a 'perfect storm' on hospitalacquired infections (HAIs) among hospitalised patients at any point in time throughout the globe. HAI is defined as an infection occurring in a patient during the process of care in a hospital or other healthcare facilities that is not manifested or incubating at the time of admission. ${ }^{1}$ Currently, it is a growing public health problem which concerns both the medical and the general community, and
Strengths and limitations of this study

- To the best of our knowledge, this is the first prospective study that examines the incidence and risk factors of hospital-acquired infections (HAls) among paediatric patients in Ethiopia.

- We did not use laboratory culture to isolate organisms as a guide in addition to the clinical criteria to confirm the results of HAls-which could have affected our results.

- In this study, we focused on a small number of risk factors for HAls; some important variables were not included as well.

a rising issue for patient safety and quality of care in every level. ${ }^{2-8}$ A study by Sheng $e t$ at ${ }^{\ominus}$ reported that $80 \%$ of hospitalised patient deaths were linked to nosocomial infection. Available evidences also showed that financial burden, increased resistance of microorganisms to antimicrobials, prolonged hospital stay and sometimes deaths, are caused by HAIs. ${ }^{10-12}$

Worldwide, it is estimated that hundreds of millions of patients every year in both developed and developing countries are affected by HAIs. ${ }^{7}$ In some Australian public hospitals, HAIs affect one in every 74 hospitalisations. ${ }^{13}$ In Europe, the total annual number of patients with HAIs in 2011-2012 was estimated around 3.2 million. The prevalence of patients with at least one HAI in acute care hospitals was $6.0 \%$ (country range 2.3\%$10.8 \%) .{ }^{14}$ Moreover, throughout Europe, HAIs accounted for 16 million additional days, with total costs estimated at approximately $€ 7$ billion. ${ }^{14-16}$ In the USA, approximately 2 million patients developed HAIs, and nearly a hundred thousand of these patients were estimated to die annually. This 
ranked HAIs as the fifth leading cause of death in acute care hospitals, and the risk of acquiring infection is 2-20 times higher in some developing countries. ${ }^{1718}$

In some developing countries, the magnitude of HAIs remains underestimated and uncertain. ${ }^{12}$ There is little information available on the epidemiology of HAIs in African countries. ${ }^{19}{ }^{20}$ Although data are sparse, evidence suggested that HAIs are considerably adding to the available high burden of infections in some sub-Saharan African countries. ${ }^{21}$ A systematic review by Nejad et $a l^{19}$ reported that hospital-wide HAI prevalence in Africa varied between $2.5 \%$ and $14.8 \%$. This review has shown that published studies were only conducted in 10 African countries-emphasised there were paucities of information available among the epidemiology of HAIs in many African countries. In addition to this, a recent review by Irek $e t a l$ indicated that there was a scarcity of studies on HAIs in Africa-of the 35 eligible articles retrieved, more than half $(n=21,60 \%)$ were from East Africa only. ${ }^{20}$ In addition, most of the HAIs literature only focused on adults, and the data on HAIs among the paediatric population in sub-Saharan Africa were hardly available. ${ }^{15} 1922$ For example, a systematic review conducted by the WHO in the year 2010 identified no reports on paediatric nosocomial bacteraemia in some African countries between 1995 and $2008 .^{15}$

In Ethiopia, little is known about the incidence and prevalence of HAIs in the neonatal and paediatric populations. Moreover, previously conducted studies focused only on adults, and many of these were limited to surgical site infections, ${ }^{23-28}$ with an estimated prevalence of $10.9 \%-{ }^{24} 66.5 \%{ }^{27}$ The overall cumulative incidence was 35.8 per 100 patients. ${ }^{26}$ Furthermore, urinary tract and bloodstream infections were found to be the most common forms of HAIs in Ethiopia. ${ }^{29-33}$ Surgery after admission, ${ }^{23} 26$ underlying medical conditions, ${ }^{23} 25$ patients with catheters, ${ }^{232526}$ patient on mechanical ventilators, ${ }^{26}$ immune-deficient patients, ${ }^{2325}$ patients' age,${ }^{263233}$ hospital types, ${ }^{32}$ the types of ward and prolonged hospitalisations ${ }^{33}$ were found to be important factors associated with increased risks of HAIs in Ethiopia.

Up to date, there are no surveillance programmes at the regional or national levels which targeted HAIs in Ethiopia. The available evidence on HAIs in the country was originated from primary studies. Moreover, to the best of our knowledge, there is not a single published report on the incidence and risk factors of HAIs among paediatric patients in Ethiopia. In order to maximise the prevention of HAIs and antimicrobial resistance in Ethiopia, epidemiological data on the incidence of HAIs are crucial because without a valid and precise assessment of HAIs, the problem remains unnoticed. Therefore, this study was designed to determine the incidence and risk factors of HAIs among paediatric patients in Goba Referral Hospital, southeast Ethiopia. The current study will help policymakers to improve their decision-making and inputs for healthcare professionals, for the improvement of patient care.

\section{METHODS}

\section{Study design and setting}

A hospital-based prospective follow-up study was conducted from 1 November 2018 to 30 June 2019, at Madda Walabu University Goba Referral Hospital, southeast Ethiopia. Goba Referral Hospital is the only referral and teaching hospital in the Bale zone, serving over 1 787575 million people. Goba Referral Hospital is located $445 \mathrm{~km}$ far from the capital city of Ethiopia. According to the 2018 annual report of Goba Referral Hospital, the average outpatient flow is over 96 661, and the annual admission is over 7886 patients, of which 1335 were admitted in the paediatric ward and neonatal intensive care unit (NICU). The hospital has a total of 127 inpatient beds—of which 30 and 15 are in the paediatric ward and NICU, respectively.

\section{Study population and eligibility criteria}

All patients (age less than 18 years) admitted to the paediatric ward and NICU were enrolled, and those who at least stayed for 48 hours, were eligible for the study. Enrolled patients who showed signs of infections and/or symptoms of infection within the first 48 hours were excluded from the study.

\section{Data collection procedures}

First, consent was sought from each of the child's parent/ guardian before commencing any study procedures. On admission, all children were evaluated clinically to exclude community-acquired infections by a paediatrician. Afterwards, sociodemographic and clinical data were collected through a structured questionnaire using individual patient chart investigation approach, accordingly, a detailed clinical history of patients were taken and recorded. Patients with no new signs or symptoms of infection after the first 48 hours from admission were included and followed prospectively for the development of HAIs during their stay in the hospital. Data were collected from enrolled patients on a daily basis: children were followed by a paediatrician daily, charts were reviewed, and discussions with nurses and physician caring for the patients were held. HAIs were confirmed by senior paediatrician specialists working in the respective NICU and paediatric ward (figure 1).

Data were collected by trained physicians and one paediatrician. The Centers for Disease Control and Prevention (CDC)/National Health Care Safety Network surveillance definition for HAIs was used. ${ }^{34}$ In this study, the usage of any antimicrobials and information on the use of different medical devices at the time of hospital admission and before the diagnosis of HAIs were recorded, respectively (see online supplemental file 1 ).

\section{Data quality control}

The data collection tool was adapted from different related pieces of literature based on the available evidences of HAIs. ${ }^{1232632}$ To ensure the quality of data, the data collection tool was pretested before the data 


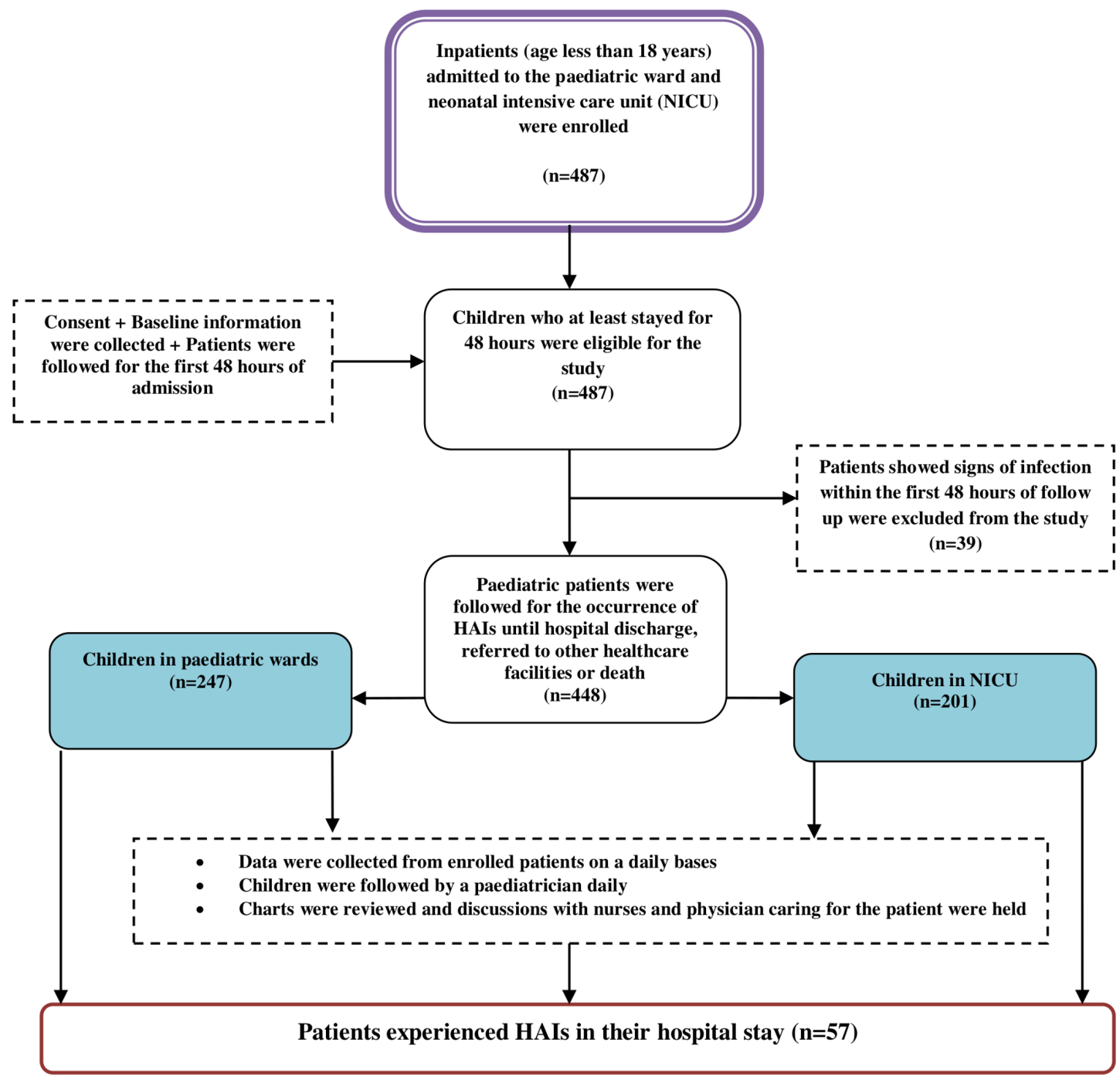

Figure 1 A flow chart of sampling procedure. HAls, hospital-acquired infections.

collection period. The training was given for data collectors on the study procedures, and with practical exercise sessions. Data collection was closely supervised by a principal investigator, and the collected data were checked for completeness, accuracy and consistency. In order to minimise the potential effects of confounder variables, multivariable logistic regression model was used, and analyses were adjusted to known confounder, such as age. In addition, the researchers try to reduce selection bias by including all admitted patients in our follow-ups. Moreover, to reduce the effect of observer bias, the data collectors have no preconceived expectations of what they should find in an examination.

\section{Operational definition}

HAI-a localised or systemic condition that results from an adverse reaction in the presence of an infectious agent or its toxin, and occurring 48 hours or longer after hospital admission, which was not incubating at the time of admission. ${ }^{14} 1923263234$

Severe anaemia-haemoglobin $<50 \mathrm{~g} / \mathrm{L}$ (for patients older than 28 days) or haemoglobin $<90 \mathrm{~g} / \mathrm{L}$ (for neonates).
Late-onset neonatal sepsis-infection occurring after birth, but excluding infections known to have been transmitted across the placenta.

\section{Study variables}

The outcome variable of the study was the occurrence of HAIs. The presence of HAIs was confirmed when the patients met the criteria for signs and symptoms determined by the $\mathrm{CDC},{ }^{34}$ where the independent variables included: sociodemographic characteristics (age of the child, sex, place of residence and previous hospitalisation), and clinical and other related variables (duration of hospitalisation, insertion of a urinary catheter, presence of peripheral intravenous catheter, received antimicrobial, American Society of Anesthesiology classification, intubation, surgery after admission, underline disease refers to severe acute malnutrition (SAM) presented at the time of admission, mechanical ventilator and HIV status).

\section{Data processing and analysis}

Data were entered into Epi-data V.3.1 and exported to Stata V.14 statistical software for further analysis. Descriptive 


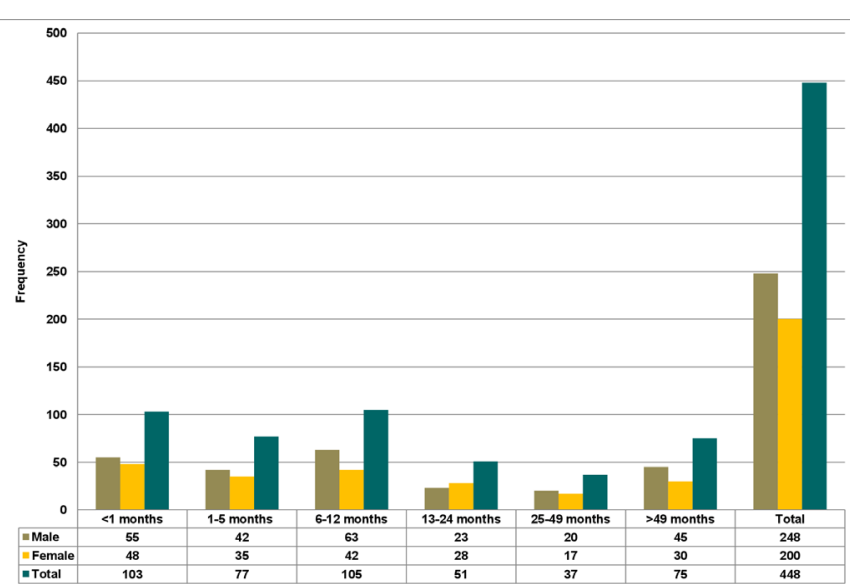

Figure 2 Bar graph showing the age distribution of study participants by sex.

statistics were computed to present the frequency distribution of important variables. The cumulative incidence (incidence proportion) was calculated as the number of new HAI cases per person in the population over a defined period of time; and it is the probability of developing HAIs over a stated study period (8 months). We estimated the incidence rate as the number of HAI cases per unit of time, and the denominator represents the total amount of time 'at-risk' without experiencing HAIs for all children whom were being followed for 8 months. The incidence rate of HAIs was reported per 1000 patient days. Multivariable logistic regression was used to identify factors with an increased risk of HAIs. Variables, that were assumed confounders based on their statistical significant result in the bivariate analysis, were included in the multivariable model. An adjusted risk ratio (ARR) with a $95 \%$ CI was used to determine the strength of association. A p value of $<0.05$ was used to declare statistical significances. Multicollinearity diagnosis was performed between categorical variables by looking at values of variance inflation factors. The final model fitness was assessed by using the Hosmer-Lemeshow goodness of fit test.

\section{Patient and public involvement}

Patients and the public were not involved in the planning, designing and interpreting of these data analyses.

\section{RESULTS}

\section{Sociodemographic characteristics of the study participants}

A total of 487 paediatric patients were enrolled in this study. However, 39 paediatric patients showed signs of infections and/or symptoms of the infection within the first 48 hours, and were excluded from the study. The remaining 448 paediatric patients were followed up for the occurrence of HAIs until their hospital discharge, referred to other healthcare facilities or death. Of the total patients included in the study, $201(44.9 \%)$ were from the NICU, and the rest were from the paediatric ward. Two hundred forty-eight $(55.4 \%)$ of the study participants were men with an overall male-to-female ratio of 1.24:1.
Also, the median age of the participants was 8 months (IQR: 2-26 months). In addition, the age distribution of the study participants by sex was presented in figure 2 . Moreover, $390(71.2 \%)$ of the study participants were from rural areas. The median hospital stay of the patients was 6 days (IQR: 3-9 days), and among them, 24 (5.4\%) died. The overall incidence density rate of the admitted paediatric mortality was 7.44 per 1000 paediatric days of follow-ups (table 1).

\section{Clinical characteristics of patients}

In this study, 46 (10.3\%) of the participants had histories of hospitalisations within the last 30 days. Fifty-four $(12.1 \%)$ of the children were diagnosed with SAM at the time of their admission. Severe anaemia was reported among 41 (9.2\%) respondents. Overall, 171 (38.2\%) patients received antimicrobials at the time of the study (table 1).

\section{Incidence and type of HAI}

During the study period, 448 paediatric patients were followed for a total of 3227 patient days. A total of 57 patients experienced HAIs, and none of the study participants were identified with more than one episode of HAIs. The mean time of diagnosis of HAIs in Goba Referral Hospital is 7.20 (95\% CI 6.72 to 7.66 ) patient days. The overall incidence rate of HAIs was 17.7 per 1000 paediatric days of follow-ups, while the cumulative incidence was $12.7 \%$ (95\% CI $9.8 \%$ to $15.8 \%$ ) over 8 months. The mean length of stay for the infected paediatric patients was 11.5 days (95\% CI 9.5 to 13.4), while it was lower for the remaining patients, at 6.5 days.

Table 2 illustrates the proportion of HAIs among the paediatric patients in Goba Referral Hospital. Hospitalacquired pneumonia (HAP) was the most common type of HAI which was observed among the paediatric patients with a proportion of $56.1 \%$ (95\% CI $43.9 \%$ to $68.4 \%$ ), followed by late-onset neonatal sepsis $10.5 \%$ (95\% CI $3.5 \%$ to $19.3 \%$ ), and the least HAIs observed were early onset of neonatal sepsis and surgical site infections, with an overall proportion of $1.8 \%$ each. In this study, the stratification of the types of HAIs by ward of admission revealed significant variability ( $p$ value $=0.007$ ) (figure 3 ).

\section{Risk factors of HAls}

Table 3 showed the risk factors of HAIs among the paediatric patients in Goba Referral Hospital. Bivariate analysis of RR has indicated that hospital duration ( $>6$ days), patients who received antimicrobial medications, presence of drainage tubes and children diagnosed with SAM were predisposed to HAIs.

In the adjusted model, the risk of HAIs was 2.58 times more likely to be higher among children who stayed longer than or equal to 6 days (median day) than those who stayed less (ARR: 2.58, 95\% CI 1.72 to 4.38 ). Patients with SAM conditions had 2.83 times higher risks of developing HAIs compared with its counterparts (ARR: $2.83,95 \%$ CI 1.61 to 4.97$)$. Sociodemographic and some 
Table 1 Demographic and clinical characteristics of patients who participated in the study in Goba Referral Hospital, southeast Ethiopia $2019(n=448)$

\begin{tabular}{|c|c|c|}
\hline Variables & Category & n (\%) \\
\hline \multicolumn{3}{|c|}{ Patient age, median (IQR): 8 months (2-26 months) } \\
\hline \multirow[t]{2}{*}{ Sex } & Male & $248(55.4)$ \\
\hline & Female & $200(44.6)$ \\
\hline \multirow[t]{2}{*}{ Ward } & $\begin{array}{l}\text { Neonatal intensive } \\
\text { care unit }\end{array}$ & $201(44.9)$ \\
\hline & Paediatrics & $247(55.1)$ \\
\hline \multirow[t]{2}{*}{ Resident } & Urban & $129(28.8)$ \\
\hline & Rural & $319(71.2)$ \\
\hline \multirow[t]{2}{*}{ Previous hospitalisation* } & Yes & $46(10.3)$ \\
\hline & No & $402(89.7)$ \\
\hline \multirow[t]{2}{*}{ Mechanical ventilation } & Yes & $76(17.0)$ \\
\hline & No & $372(83.0)$ \\
\hline \multirow{2}{*}{$\begin{array}{l}\text { Presence of peripheral } \\
\text { intravenous cathetert }\end{array}$} & Yes & $430(96.0)$ \\
\hline & No & $18(4.0)$ \\
\hline \multirow{2}{*}{$\begin{array}{l}\text { Presence of urinary } \\
\text { catheters }\end{array}$} & Yes & $9(2.0)$ \\
\hline & No & $439(98.0)$ \\
\hline \multirow[t]{2}{*}{ Drainage tube inserted ${ }^{\star *}$} & Yes & $53(11.8)$ \\
\hline & No & 395 (88.2) \\
\hline \multirow{2}{*}{$\begin{array}{l}\text { Underlying severe acute } \\
\text { malnutrition (SAM) } \\
\text { diseases } \neq\end{array}$} & Yes & $54(12.1)$ \\
\hline & No & $394(87.9)$ \\
\hline \multirow[t]{2}{*}{ Surgery after admission } & Yes & $47(10.5)$ \\
\hline & No & $401(89.5)$ \\
\hline \multirow{3}{*}{$\begin{array}{l}\text { Patient received } \\
\text { antimicrobials } \S\end{array}$} & Yes & $171(38.2)$ \\
\hline & No & $221(49.3)$ \\
\hline & Unknown & $56(12.5)$ \\
\hline \multirow[t]{3}{*}{ Severe anaemia } & Yes & $41(9.2)$ \\
\hline & No & $375(83.7)$ \\
\hline & Unknown & $32(7.1)$ \\
\hline \multirow{2}{*}{$\begin{array}{l}\text { Hospital duration (median } \\
\text { day) }\end{array}$} & $\leq 6$ & $237(52.9)$ \\
\hline & $>6$ & $211(47.1)$ \\
\hline \multirow[t]{3}{*}{ HIV status } & Positive & $2(0.4)$ \\
\hline & Negative & $393(87.7)$ \\
\hline & Not tested & $53(11.8)$ \\
\hline \multirow{5}{*}{$\begin{array}{l}\text { American Society } \\
\text { of Anesthesiology } \\
\text { classification }\end{array}$} & $\begin{array}{l}\text { Normally health } \\
\text { patient }\end{array}$ & $72(16.1)$ \\
\hline & $\begin{array}{l}\text { Patient with mild } \\
\text { systemic diseases }\end{array}$ & $235(52.5)$ \\
\hline & $\begin{array}{l}\text { Severe systemic } \\
\text { disease that is not } \\
\text { incapacitating }\end{array}$ & $100(22.3)$ \\
\hline & $\begin{array}{l}\text { Incapacitating } \\
\text { systemic disease } \\
\text { that is a constant } \\
\text { threat to life }\end{array}$ & $36(8.0)$ \\
\hline & Unknown & $5(1.1)$ \\
\hline
\end{tabular}

Continued
Table 1 Continued

\begin{tabular}{lll}
\hline Variables & Category & $\mathbf{n}(\%)$ \\
\hline Gestational age $(\mathrm{n}=191)$ & $<37$ weeks & $83(43.5)$ \\
& $\geq 37$ weeks & $108(56.5)$ \\
Birth weight $(\mathrm{n}=191) \mathfrak{}$ & $<2500 \mathrm{~g}$ & $46(24.1)$ \\
& $\geq 2500 \mathrm{~g}$ & $145(75.9)$
\end{tabular}

*History of the hospitalisation for either the same as the current reason of admission or other ailments within the last 30 days. †Peripheral intravenous catheter: a peripheral intravenous catheter is inserted into small peripheral veins to provide access to administer intravenous fluids and medications. $\ddagger$ SAM diagnosed at the time of hospital admission. $\S$ The use of antimicrobials before admission either through intravenous, intramuscular or oral administration.

IAny neonate weighing less than $2500 \mathrm{~g}$ at birth irrespective of gestational age was considered low birth weight.

${ }^{* *}$ Drainage tube: insertion of a chest tube, endotracheal and nasogastric intubation.

clinically related confounders could not show any statistically significant associations (table 4 ).

In this study, we estimated the attributable risk, which estimates the excess risk of disease in those exposed compared with those non-exposed. The excess occurrence of HAIs among children with underlying SAM diseases attributable to their SAM condition is 13 per 100 (table 4).

\section{DISCUSSION}

HAIs are current global challenges that increase morbidities, mortality and massive economic cost. ${ }^{35-39}$ Yet, there remain limited data on the occurrences of HAIs in hospitalised paediatric patients in sub-Saharan Africa, including Ethiopia. This study was designed to determine the incidence and risk factors of HAIs among paediatric patients in a teaching hospital, southeast Ethiopia. The overall incidence rate of HAIs was 17.75 per 1000 paediatric days of follow-up while the cumulative incidence was $12.7 \%$ (95\% CI $9.8 \%$ to $15.8 \%$ ) over 8 months. Children who stayed longer than the median day (6 days) in the hospital, and children with underlying disease conditions (SAM), had higher risks of developing HAIs.

In this study, the overall incidence rate of HAIs was 17.7 per 1000 paediatric days of follow-ups. This finding is lower than a related prospective study by Ali et al from southwest Ethiopia, which reported an incidence of HAIs of 28.15 per 1000 patient days. ${ }^{39}$ The difference might be associated with the nature of this study which involved only paediatric patients including those in intensive care; whereas, the study by Ali et $a l^{39}$ included adult study participants. Also, variations in some studies could be attributed to differences in geographical locations and the study settings (as in the case of Ali $e t a l^{39}$ where the study they included a specialised hospital). A previous before-and-after study conducted in a teaching hospital in Indonesia 
Table 2 Proportion of hospital-acquired infections among paediatric patients in Goba Referral Hospital, Ethiopia ( $\mathrm{n}=57$ )

\begin{tabular}{llll}
\hline Hospital-acquired infections & Number & Proportion & $\mathbf{9 5 \%} \mathbf{C l}$ \\
\hline Pneumonia/lower respiratory tract infections* & 32 & 56.1 & 43.9 to 68.4 \\
\hline Late-onset neonatal sepsis & 6 & 10.5 & 3.5 to 19.3 \\
\hline Intravenous line site infections & 5 & 8.8 & 1.8 to 15.8 \\
Urinary tract infections & 4 & 7.0 & 1.8 to 14.0 \\
Systemic infections & 4 & 7.0 & 1.8 to 14.0 \\
Skin/soft tissue infections & 2 & 3.5 & 0.0 to 8.8 \\
Measles & 2 & 3.5 & 0.0 to 8.8 \\
\hline Early-onset neonatal sepsis & 1 & 1.8 & 0.0 to 5.3 \\
\hline Surgical site infections & 1 & 1.8 & 0.0 to 7.0 \\
\hline
\end{tabular}

*including ventilator-associated pneumonia (VAP) ( $n=7)$ and VAP developed in 9.21\% (7/76) of children undergoing mechanical ventilation.

involved children whom were admitted to the paediatric intensive care unit (ICU) and paediatric ward, reported the incidence density rate of HAI 29.1 per 1000 patient days, which is similar to our findings. ${ }^{36}$

One of our findings has also revealed that the overall cumulative incidence of HAIs was $12.7 \%$; this is comparable to those reported from a study in the USA $(11.9 \%)^{37}$ which was conducted in the paediatric ICU, and in Poland $(13.3 \%) .{ }^{38}$ Also, the present $12.7 \%$ of HAIs noted in our study population fell in the ranges of $9.8 \%-15.8 \%$, and is reported elsewhere, ${ }^{14} 4041$ and the WHO pooled estimated for low-income countries $10.1 \% .{ }^{18}$ Conversely, similar studies from Turkey reported a much higher prevalence of HAIs among children ranging between $22.2 \%$ and $68.4 \%,{ }^{42} 43$ and in a multicentre prospective study from Europe reported $18.5 \%^{44}$ among paediatric patients.

The present study also demonstrated that the occurrence of HAIs was higher among male participants $(52.6 \%)$ than women. This result was also supported by other studies conducted elsewhere. ${ }^{40}{ }^{45-47}$ In the same vein, one study carried out by Koch $e t a t^{48}$ in Norway reported that men present higher overall HAI prevalence than women.

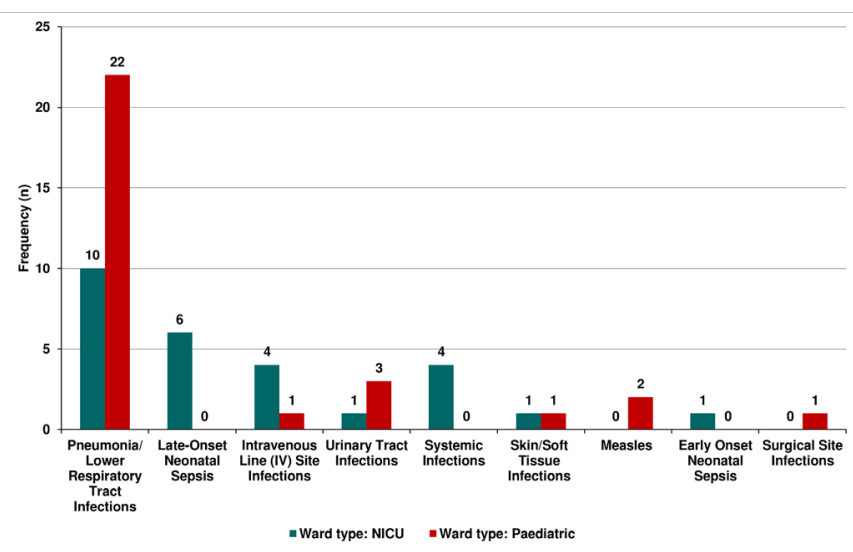

Figure 3 Bar graph showing the type of HAls by type of admission ward. HAls, hospital-acquired infections; NICU, neonatal intensive care unit.
The most common type of HAI observed in this study was HAP, which contributed to a proportion of $56.1 \%$ of the total HAIs. It may not be a surprise to see such a high proportion of HAI in the NICU and paediatric ward since most of the patients admitted in intensive care are incapacitated and critical. Moreover, compared with adults, infants and neonates are immunologically immature, and in many cases, vulnerable. ${ }^{49} 50$ The finding was similar to the study done in Tikur Anbessa Hospital, Ethiopia. ${ }^{33}$ It is also true for other settings-in Iran $43.7 \%,{ }^{51}$ India $50 \%,{ }^{52}$ Vietnam 41.9\%, ${ }^{53}$ Morocco $34.5 \%,{ }^{54}$ Saudi Arabia $46.7 \%{ }^{55}$ China $52.2 \%{ }^{56}$ and in a European multicentre prospective study $53 \% .{ }^{44}$ The high burden of HAP among hospitalised paediatric patients has important implications in terms of length of hospital stay, healthcare cost and mortality. The overall mortality attributed to HAP has been as high as $30 \%-50 \% .{ }^{57}$ In this study, ventilatorassociated pneumonia (VAP) developed in $9.21 \%(7 / 76)$ of children who underwent mechanical ventilation. Our estimate is in line with studies conducted on children reporting VAP, which occurred in $3 \%-10 \%$ of ventilated paediatric ICU patients. $3658-60$

In this study, the risk of developing HAIs was three times higher among children who stayed longer than or equal to the median 6 days than their counterparts. Despite this positive association, this is not a proof that decreasing the length of stay neither increasing admission days increases/decreases the occurrence of HAIs. Possible revered causation may be one of the mechanisms why this prolonged length of stay is associated with HAIs. Moreover, there is evidence that HAIs cause a prolonged length of stay. ${ }^{61-65}$ In our findings, the presence of underlying diseases, such as SAM, was recognised as the main risk factor for HAIs. This was consistent with the finding from another study in Ethiopia, ${ }^{24}$ that underlying illnesses increased the susceptibility of patients and predisposed them to infections secondary to the reduction of the patient's immune response that exacerbated the illnesses through which in many cases, had significant factors that contributed more to the acquisition of HAIs in neonates and paediatric patients. ${ }^{416667}$ 
Table 3 Bivariate association of factors for the occurrence of hospital-acquired infections (HAls) among paediatric patients in Goba Referral Hospital, southeast Ethiopia 2019 ( $n=448)$

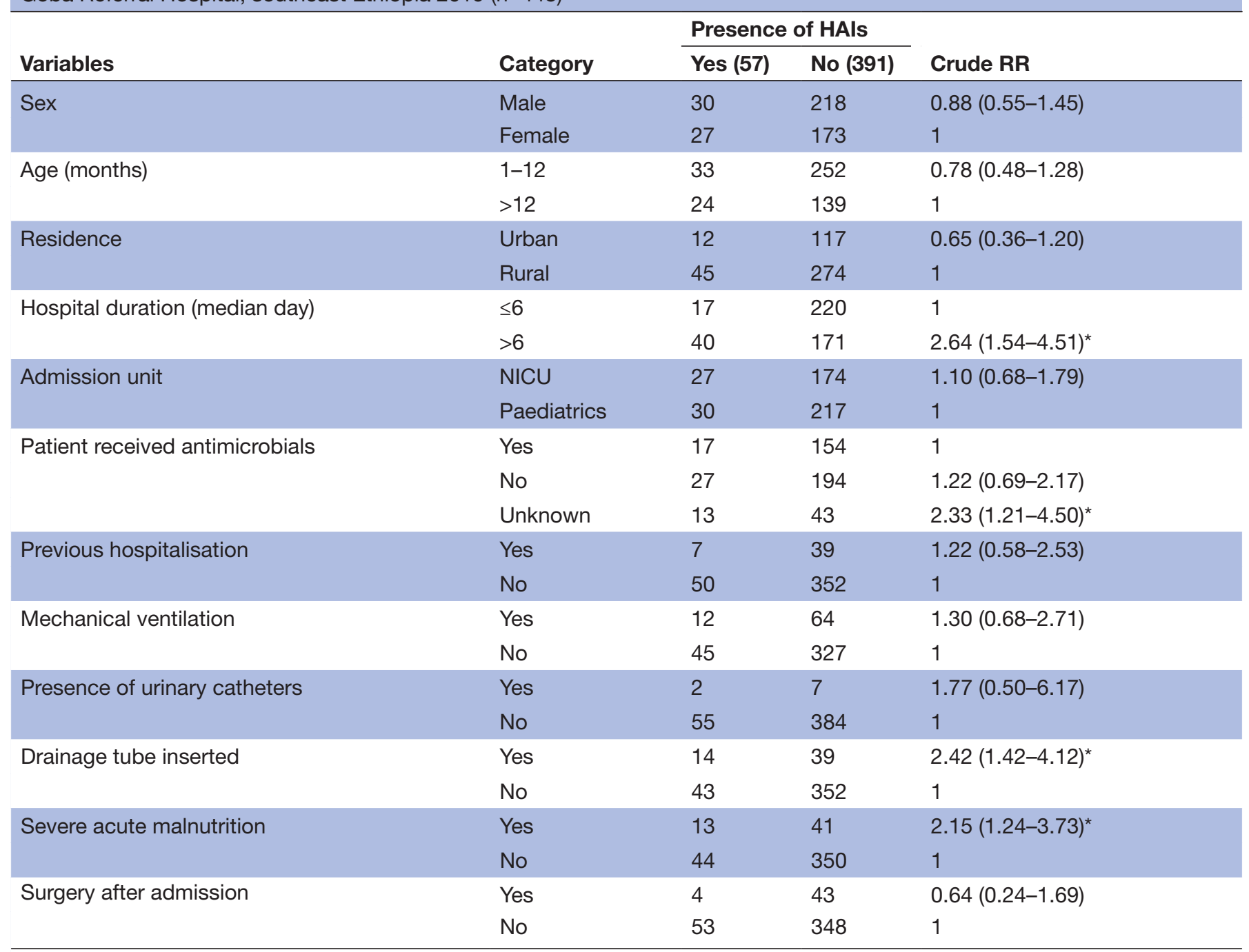

${ }^{*} \mathrm{P}$ value is $<0.05$ (crude).

$\mathrm{NICU}$, neonatal intensive care unit; RR, risk ratio.

\section{Limitations of the study}

Several limitations on this prospective study needed to be considered. First, we did not assess the healthcare workers' infection prevention practices that would have been associated with the prevalence of HAIs. Second, the researchers did not examine the number of HAIs after the patients were discharged. Third, despite that we followed the patients until their discharge, the full burden of HAI could not be captured in this specific study, and is limited to in-hospital assessment only, leaving outpatients whom may have potentially developed HAIs after discharge. Fourth, we focused on a small number of risk factors for HAIs and some important variables were not included. Fifth, the used analysis does not take any time-varying risk into account. Sixth, since there was limited information on the patients' medical record folders, more social determinant variables were not collected. In addition, this study is not free from the effects of information bias as we do not use 'blinding'. Another limitation of the study is that we could not adjust the results for the effect of social determinant variables on HAIs because the information on these social determinant variables was not collected in our study. Finally, laboratory cultures to isolate organisms as a guide were not used, in addition to the clinical criteria, to confirm the results of HAIs because of financial constraints, laboratory facilities and expertise. Given the lack of microbiology data, endogenous infections may be misclassified as HAIs. Since the study was conducted in a teaching referral hospital, the generalisation of the study findings was limited to these facilities.

\section{CONCLUSIONS}

The present study revealed that the cumulative incidence of HAIs was 13 per 100 admitted children, and the overall incidence rate of HAIs was 17.75 per 1000 paediatric days. Length of stay in the hospital and patients with SAM conditions were associated with increased risk of HAIs. 
Table 4 Multivariable logistic regression analysis on factors associated with hospital-acquired infections (HAls) among patients in Goba Referral Hospital, southeast Ethiopia $2019(n=448)^{*} \ddagger$

\begin{tabular}{|c|c|c|c|c|}
\hline Variables & Category & Patient with HAls $(n=57)$ & Adjusted RR & Attributable risk§ \\
\hline Hospital duration & $>6$ & 40 & $2.58(1.52-4.38) \dagger$ & 0.12 \\
\hline \multirow{2}{*}{ Patient received antimicrobials } & No & 27 & $1.25(0.71-2.19)$ & \\
\hline & Unknown & 13 & $1.93(0.84-4.42)$ & \\
\hline Drainage tube inserted & No & 43 & 1 & \\
\hline \multirow[t]{2}{*}{ Severe acute malnutrition } & Yes & 13 & $2.83(1.61-4.97) \dagger$ & 0.13 \\
\hline & No & 44 & 1 & \\
\hline
\end{tabular}

*Hosmer-Lemeshow test $(p=0.166)$.

$\dagger P$ value of $<0.05$ (adjusted).

$\ddagger$ Adjusted for age, sex, admission unit, mechanical ventilation and presence of a urinary catheter.

$\S$ Attributable risk is the difference between the risk HAls in the exposed group and the unexposed group.

$\mathrm{RR}$, risk ratio.

Further studies are strongly recommended to identify other important factors including isolating of bacterial, fungal and viral agents responsible for HAIs in the region.

\section{Author affiliations}

'Department of Public Health, School of Health Science, Madda Walabu University, Bale Robe, Ethiopia

${ }^{2}$ Department of Pediatrics, School of Medicine, Madda Walabu University, Bale Goba, Ethiopia

${ }^{3}$ Department of Medical Laboratory Science, School of Medicine, Madda Walabu University, Bale Goba, Ethiopia

${ }^{4}$ Department of Nursing, School of Medicine, Madda Walabu University, Bale Goba, Ethiopia

Correction notice This article has been corrected since it first published. The provenance and peer review statement has been included.

Twitter Yohannes Tekalegn @yohannesefa

Acknowledgements First and foremost, we would like to thank all the participants of this study, data collectors, Goba Referral Hospital staff and paediatric ward coordinators. Also, we would like to extend our sincere gratitude to Madda Walabu University for the financial support.

Contributors BS has made substantial contributions to conception and design acquisition of data, analysis and interpretation of data. He has written the draft manuscript and provided final approval of the version to be published. FS, DA, ENG, GN, AK, DW, YT, DZ and BJEQ have made substantial contributions to design acquisition of data and analysis, and interpretation of data, revised the article critically for important intellectual content, and provided final approval of the version to be published. All authors read and approved the final manuscript.

Funding The data collection was supported by Madda Walabu University Research Community Engagement and Technology Transfer Directorate; grant number: NA.

Disclaimer The funders had no role in the study design, data collection and analysis, decision to publish or preparation of the manuscript.

Competing interests None declared.

Patient consent for publication Not required.

Ethics approval Ethical clearance was obtained from the Ethical Review Committee of Madda Walabu University (ref no: RMW 14/66/64) and a formal letter from Madda Walabu University Research Community Engagement and Technology Transfer Vice President Office was submitted. Written consent from the parents/legal guardians was obtained after explaining the objectives of the study. Identified paediatric patients having hospital-acquired infections were formally communicated to the physicians and nurses who were in charge of the patients for additional healthcare services. Throughout the data collection period, confidentiality and privacy of the patients were observed, and a unique identification code rather than their names was substituted.

Provenance and peer review Not commissioned; externally peer reviewed.

Data availability statement Data are available upon reasonable request. All data relevant to the study are included in the article or uploaded as supplemental information. Data will be available upon request from the corresponding authors.

Supplemental material This content has been supplied by the author(s). It has not been vetted by BMJ Publishing Group Limited (BMJ) and may not have been peer-reviewed. Any opinions or recommendations discussed are solely those of the author(s) and are not endorsed by BMJ. BMJ disclaims all liability and responsibility arising from any reliance placed on the content. Where the content includes any translated material, BMJ does not warrant the accuracy and reliability of the translations (including but not limited to local regulations, clinical guidelines, terminology, drug names and drug dosages), and is not responsible for any error and/or omissions arising from translation and adaptation or otherwise.

Open access This is an open access article distributed in accordance with the Creative Commons Attribution Non Commercial (CC BY-NC 4.0) license, which permits others to distribute, remix, adapt, build upon this work non-commercially, and license their derivative works on different terms, provided the original work is properly cited, appropriate credit is given, any changes made indicated, and the use is non-commercial. See: http://creativecommons.org/licenses/by-nc/4.0/.

\section{ORCID iDs}

Biniyam Sahiledengle http://orcid.org/0000-0002-1114-4849

Yohannes Tekalegn http://orcid.org/0000-0001-6628-8180

\section{REFERENCES}

1 World Health Organization. Prevention of hospital-acquired infections: a practical guide. Geneva: World Health Organization, 2002.

2 Emerson CB, Eyzaguirre LM, Albrecht JS, et al. HealthcareAssociated infection and hospital readmission. Infection Control \& Hospital Epidemiology 2012;33:539-44

3 Bates DW, Larizgoitia I, Prasopa-Plaizier N, et al. Global priorities for patient safety research. BMJ 2009;338:b1775

4 WHO. Who guidelines on hand hygiene in health care: a summary. Geneva, Switzerland: World Health Organization, 2009.

5 Geffers C, Gastmeier P. Nosocomial infections and multidrugresistant organisms in Germany: epidemiological data from kiss (the hospital infection surveillance system). Dtsch Ärztebl Int 2011;108:87-93.

6 Lul R. Prevention and control of Hospital-Related infections in low and middle income countries. Open Infect Dis J 2010;4:125-31. 
7 Allegranzi B, Storr J, Dziekan G, et al. The first global patient safety challenge "clean care is safer care": from launch to current progress and achievements. J Hosp Infect 2007;65 Suppl 2:115-23.

8 Rosenthal VD, Maki DG, Mehta Y, et al. International nosocomial Infection control consortiu (INICC) report, data summary of 43 countries for 2007-2012. device-associated module. Am J Infect Control 2014;42:942-56.

9 Sheng W-H, Wang J-T, Lin M-S, et al. Risk factors affecting inhospital mortality in patients with nosocomial infections. J Formos Med Assoc 2007;106:110-8.

10 Pittet $D$, Donaldson L. Clean care is safer care: a worldwide priority. Lancet 2005;366:1246-7.

11 Uwaezuoke S, Obu H. Nosocomial infections in neonatal intensive care facilities: cost-effective control strategies in resource-limited countries. Nigeria J Pediatr 2013;40:125-32.

12 Allegranzi B, Pittet D. Preventing infections acquired during healthcare delivery. Lancet 2008;372:1719-20.

13 ACSQHC. Selected best practices and suggestions for improvement for clinicians and health system managers. Healthcare Acquired Infections. Australian Commission on Safety and Quality in Health Care; March 2018. Available: https://www.safetyandquality.gov.au/ sites/default/files/migrated/Healthcare-associated-infection-detailedfact-sheet.pdf

14 European Centre for Disease Prevention and Control (ECDC). Point prevalence survey of healthcare associated infections and antimicrobial use in European acute care hospitals. Stockholm: ECDC, 2013.

15 Allegranzi B, Nejad SB, Combescure C, et al. Burden of endemic health-care-associated infection in developing countries: systematic review and meta-analysis. The Lancet 2011;377:228-41.

16 Magill SS, Hellinger W, Cohen J, Shelley S, Walter H, Robyn K, et al. Prevalence of healthcare-associated infections in acute care hospitals in Jacksonville, Florida. Infect Control Hosp Epidemiol 2012;33:283-91.

17 Nelson S, Stone PW, Jordan S, et al. Patient safety climate: variation in perceptions by infection preventionists and quality directors. Interdiscip Perspect Infect Dis 2011;2011:1-7.

18 World Health organization (WHO). Infection prevention and control in health care: time for collaborative action regional Committee for the eastern Mediterranean. EM/RC57/6. Geneva: WHO, 2010.

19 Bagheri Nejad S, Allegranzi B, Syed SB, et al. Health-careassociated infection in Africa: a systematic review. Bull World Health Organ 2011;89:757-65.

20 Irek EO, Amupitan AA, Obadare TO, et al. A systematic review of healthcare-associated infections in Africa: an antimicrobial resistance perspective. Afr J Lab Med 2018;7:1-9.

21 Rothe C, Schlaich C, Thompson S. Healthcare-Associated infections in sub-Saharan Africa. J Hosp Infect 2013;85:257-67.

22 Zaidi AKM, Huskins WC, Thaver D, et al. Hospital-Acquired neonatal infections in developing countries. Lancet 2005;365:1175-88.

23 Yallew WW, Kumie A, Yehuala FM. Risk factors for hospital-acquired infections in teaching hospitals of Amhara regional state, Ethiopia: a matched-case control study. PLoS One 2017;12:e0181145.

24 Mulu W, Kibru G, Beyene G, et al. Postoperative nosocomial infections and antimicrobial resistance pattern of bacteria isolates among patients admitted at Felege Hiwot referral Hospital, Bahirdar, Ethiopia. Ethiop J Health Sci 2012;22:7-18.

25 Gedebou M, Habte-Gabr E, Kronvall G, et al. Hospital-acquired infections among obstetric and gynaecological patients at Tiku Anbessa Hospital, Addis Ababa. J Hosp Infect 1988;11:50-9.

26 Endalafer N, Gebre-Selassie S, Kotiso B. Nosocomial bacterial infections in a tertiary hospital in Ethiopia. J Infect Prev 2011;12:38-43.

27 Feleke T, Eshetie S, Dagnew M, et al. Multidrug-resistant bacterial isolates from patients suspected of nosocomial infections at the University of Gondar comprehensive specialized Hospital, Northwest Ethiopia. BMC Res Notes 2018;11:602.

28 Amenu D, Belachew T, Araya F. Surgical site infection rate and risk factors among obstetric cases of jimma university specialized Hospital, Southwest Ethiopia. Ethiop J Health Sci 2011;21:91-100.

29 Melaku S, Gebre-Selassie S, Damtie M, et al. Hospital acquired infections among surgical, gynaecology and obstetrics patients in Felege-Hiwot referral Hospital, Bahir Dar, Northwest Ethiopia. Ethiop Med J 2012:50:135-44.

30 Messele G, Woldemedhin Y, Demissie M, et al. Common causes of nosocomial infections and their susceptibility patterns in two hospitals in Addis Ababa. Ethiop J Health Biomed Sci 2009;2:3-8.

31 Melaku S, Kibret M, Abera B, et al. Antibiogram of nosocomial urinary tract infections in Felege Hiwot referral Hospital, Ethiopia. Afr Health Sci 2012;12:134-9.
32 Yallew WW, Kumie A, Yehuala FM, Walelegn W, Abera K, Feleke M. Point prevalence of hospital-acquired infections in two teaching hospitals of Amhara region in Ethiopia. Drug Healthc Patient Saf 2016:8:71-6.

33 Mikyas D, Sileshi L. The prevalence of nosocomial infections and associated risk factors in pediatric patients in Tikur Anbessa Hospital. Ethiopian J Pediatr and Child Health 2008;5:4-16.

34 Horan TC, Andrus M, Dudeck MA. CDC/NHSN surveillance definition of health care-associated infection and criteria for specific types of infections in the acute care setting. Am J Infect Control 2008;36:309-32.

35 Joram N, de Saint Blanquat L, Stamm D, et al. Healthcare-associated infection prevention in pediatric intensive care units: a review. Eur J Clin Microbiol Infect Dis 2012;31:2481-90.

36 Murni IK, Duke T, Kinney S, et al. Reducing hospital-acquired infections and improving the rational use of antibiotics in a developing country: an effectiveness study. Arch Dis Child 2015:100:454-9.

37 Grohskopf LA, Sinkowitz-Cochran RL, Garrett DO, et al. A national point-prevalence survey of pediatric intensive care unit-acquired infections in the United States. J Pediatr 2002;140:432-8.

38 Deptuła A, Trejnowska E, Ozorowski T, et al. Risk factors for healthcare-associated infection in light of two years of experience with the ECDC point prevalence survey of healthcare-associated infection and antimicrobial use in Poland. $J$ Hosp Infect 2015;90:310-5.

39 Ali S, Birhane M, Bekele S, et al. Healthcare associated infection and its risk factors among patients admitted to a tertiary hospital in Ethiopia: Iongitudinal study. Antimicrob Resist Infect Control 2018;7:2.

40 Askarian M, Yadollahi M, Assadian O. Point prevalence and risk factors of hospital acquired infections in a cluster of universityaffiliated hospitals in Shiraz, Iran. $J$ Infect Public Health 2012;5:169-76.

41 Olivier C, Kunneke H, O'Connell N, et al. Healthcare-Associated infections in paediatric and neonatal wards: a point prevalence survey at four South African hospitals. S Afr Med J 2018;108:418-22.

42 Aydın Teke T, Tanır G, Bayhan Gülsüm İclal, et al. Clinical and microbiological features of resistant gram-negative bloodstream infections in children. $J$ Infect Public Health 2017;10:211-8.

43 Atici S, Soysal A, Kepenekli Kadayifci E, Kadayifci EK, et al. Healthcare-associated infections in a newly opened pediatric intensive care unit in turkey: results of four-year surveillance. $J$ Infect Dev Ctries 2016;10:254-9.

44 Raymond J, Aujard Y. Nosocomial infections in pediatric patients: a European, multicenter prospective study. European Study Group. Infect Control Hosp Epidemiol 2000;21:260-3.

45 Offner PJ, Moore EE, Biffl WL. Male gender is a risk factor for major infections after surgery. Arch Surg 1999:134:935-40.

46 Wałaszek M, Kosiarska A, Gniadek A, et al. The risk factors for hospital-acquired pneumonia in the intensive care unit. Przegl Epidemiol 2016;70:15-20.

47 Ahmed M, Alam SN, Khan O, et al. Postoperative wound infection: a surgeon's dilemma. Pak J Surg 2007;23:41-7.

48 Koch AM, Nilsen RM, Eriksen HM, et al. Mortality related to hospitalassociated infections in a tertiary hospital; repeated cross-sectional studies between 2004-2011. Antimicrob Resist Infect Control 2015;4:57.

49 Brady MT. Health care-associated infections in the neonatal intensive care unit. Am J Infect Control 2005;33:268-75.

50 Saiman L. Risk factors for hospital-acquired infections in the neonatal intensive care unit. Semin Perinatol 2002;26:315-21.

51 Behzadnia S, Davoudi A, Rezai MS, et al. Nosocomial infections in pediatric population and antibiotic resistance of the causative organisms in North of Iran. Iran Red Crescent Med J 2014;16:e14562.

52 Singh S, Chaturvedi R, Garg SM, et al. Incidence of healthcare associated infection in the surgical ICU of a tertiary care hospital. Medical Journal Armed Forces India 2013;69:124-9.

53 Thu TA, Hung NV, Quang NN, et al. A point-prevalence study on healthcare-associated infections in Vietnam: public health implications. Infect Control Hosp Epidemiol 2011;32:1039-41.

54 Razine R, Azzouzi A, Barkat A, et al. Prevalence of hospital-acquired infections in the University medical center of Rabat, Morocco. Int Arch Med 2012;5:26.

55 Balkhy HH, Cunningham G, Chew FK, et al. Hospital- and community-acquired infections: a point prevalence and risk factors survey in a tertiary care center in Saudi Arabia. Int $J$ Infect Dis 2006;10:326-33.

56 Le NK, Hf W, Vu PD, et al. High prevalence of hospital-acquired infections caused by gram-negative carbapenem resistant strains in 
Vietnamese pediatric ICUs: a multi-centre point prevalence survey. Medicine 2016;95:e4099.

57 American Thoracic Society, Infectious Diseases Society of America. Guidelines for the management of adults with hospital-acquired, ventilator-associated, and healthcare-associated pneumonia. Am J Respir Crit Care Med 2005;171:388-416.

58 Almuneef M, Memish ZA, Balkhy HH, et al. Ventilator-Associated pneumonia in a pediatric intensive care unit in Saudi Arabia: a 30-month prospective surveillance. Infect Control Hosp Epidemiol 2004;25:753-8.

59 Elward AM, Warren DK, Fraser VJ. Ventilator-Associated pneumonia in pediatric intensive care unit patients: risk factors and outcomes. Pediatrics 2002;109:758-64.

60 Foglia E, Meier MD, Elward A. Ventilator-Associated pneumonia in neonatal and pediatric intensive care unit patients. Clin Microbiol Rev 2007;20:409-25.

61 Sarvikivi E, Kärki T, Lyytikäinen O, et al. Repeated prevalence surveys of healthcare-associated infections in Finnish neonatal intensive care units. J Hosp Infect 2010;76:156-60.
62 Sangrasi AK, Leghari AA, Memon A, et al. Surgical site infection rate and associated risk factors in elective general surgery at a public sector medical university in Pakistan. Int Wound J 2008;5:74-8.

63 Khaleid M, Haleim A, Zein K. Et: surgical site infections and associated risk factors in Egyptian orthopedic patients. J Am Sci 2010;6:272-80.

64 Arefian $\mathrm{H}$, Hagel S, Fischer D, et al. Estimating extra length of stay due to healthcare-associated infections before and after implementation of a hospital-wide infection control program. PLOS One 2019;14:e0217159.

65 Zhou Q, Fan L, Lai X, et al. Estimating extra length of stay and risk factors of mortality attributable to healthcare-associated infection at a Chinese university hospital: a multi-state model. BMC Infect Dis 2019;19:975.

66 Shahunja KM, Ahmed T, Faruque ASG, et al. Experience with nosocomial infection in children under 5 treated in an urban diarrheal treatment center in Bangladesh. Glob Pediatr Health 2016:3:2333794X1663426.

67 Dramowski A, Whitelaw A, Cotton MF, Burden CMF. Burden, spectrum, and impact of healthcare-associated infection at a South African children's hospital. J Hosp Infect 2016;94:364-72. 